Research Paper

\title{
Opportunistic salpingectomy at benign gynecological surgery for reducing ovarian cancer risk: a 10-year single centre experience from China and a literature review
}

\author{
Ying Chen ${ }^{1,2,3,4 \#, 凹}$, Hui Du, \#, Lewen Bao ${ }^{1}$, Wenxin Liu ${ }^{1}$ \\ 1. Department of Gynecologic Oncology, Tianjin Medical University Cancer Institute and Hospital, Tianjin 300060, China \\ 2. Key Laboratory of Cancer Prevention and Therapy, Tianjin 300060, China \\ 3. National Clinical Research Centre of Cancer, Tianjin 300060, China \\ 4. Tianjin's Clinical Research Center for Cancer \\ 5. Department of Obstetrics and Gynecology, The Second Hospital of Hebei Medical University, Shijiazhuang, Hebei 050000, China \\ \# Y. Chen and H. Dui contributed equally to this work. \\ $\triangle$ Corresponding author: Ying Chen, M.D., Ph.D., Department of Gynecologic Oncology, Tianjin Medical University Cancer Institute and Hospital, Huanhuxi \\ Road, Hexi District, Tianjin 300060, China. E-mail: lychenying2004@126.com \\ (C) Ivyspring International Publisher. This is an open access article distributed under the terms of the Creative Commons Attribution (CC BY-NC) license \\ (https://creativecommons.org/licenses/by-nc/4.0/). See http://ivyspring.com/terms for full terms and conditions.
}

Received: 2017.05.26; Accepted: 2017.10.06; Published: 2018.01.01

\begin{abstract}
Current evidences indicate that the fallopian tube plays a major role in the pathogenesis of epithelial ovarian cancer (EOC). Salpingectomy represents a novel and potentially effective risk-reducing option. In this study, there were 1822 patients diagnosed and treated for EOC or primary peritoneal cancer (PPC) at Department of Gynecologic Oncology, Tianjin Medical University Cancer Institute and Hospital from January 1, 2007 to April 30, 2017. Among them, 198 patients with a history of gynecological surgery because of benign diseases were enrolled to analyze further. Using 1:2 case-control study, we found that the incidence of EOC was significantly decreased in the population with salpingectomy, compared to women with fallopian tube reserved $(P<0.05)$. At the same period, there were 4339 patients receiving opportunistic salpingectomy in our centre because of benign gynecological diseases. The results showed the rate of bilateral salpingectomy was annually increased from 2007 to 2017 (22.02\% to 60.22\%), which showed approximately threefold increase in a decade. In general, factors affecting the rate of salpingectomy included age, child number, menopause or not, marital status, educational status, income status, and with or without family history of tumor. Therefore, based on ten years experiences from our centre, it is recommended that physician should discuss with appropriate patients to perform opportunistic bilateral salpingectomy at the time of receiving benign gynecological surgery for preventing ovarian cancer. Moreover, the prospective, large scale and multi-centre studies to evaluate the safety and efficacy of salpingectomy as a preventive strategy for ovarian cancer warrant to conduct in the future.
\end{abstract}

Key words: fallopian tubes; ovarian cancer; salpingectomy; risk reduction

\section{Introduction}

Epithelial ovarian cancer (EOC) was the leading killer among women with gynecologic cancers. In 2017, there were 22,440 estimated new diagnoses of ovarian cancer and 14,080 deaths from the disease ${ }^{1}$. Nonspecific symptoms in early stage of disease and a lack of effective screening methods are the main reasons why more than $70 \%$ of cases are diagnosed in
FIGO stage III or IV ${ }^{2}$. Despite the progress in therapy the mortality rate remains high with a five-year overall of only $20-40 \%$ for advanced disease ${ }^{3}$. Studies reported that approximately $95 \%$ of ovarian cancers are of epithelial origin and the high-grade serous caner (HGSC) represents $75 \%$ of EOC and accounts for the majority of deaths 4, 5. Recently, collective 
literature indicated precursor lesions of HGSC originated in the fallopian tube not from ovary ${ }^{6}$. The initial evidence for the fallopian origin of ovarian cancer came from the studies of prophylactic salpingo-oophorectomy in women bearing BRCA mutations ${ }^{7}$. Detailed examination of fallopian specimens revealed dysplastic lesions, later designated as serous tubal intraepithelial carcinoma (STIC) located in the fimbrial end ${ }^{8}$.

At present, a viewpoint is generally understood that the junction of the fallopian tube epithelium with the ovarian mesothelium might be a potential site of ovarian carcinogenesis, similar to the uterine, cervical, gastroesophageal or anorectal junctions 9,10 . Thus, removal of the fallopian tubes at the time of pelvic or abdominal surgery for a benign condition (i.e. opportunistic salpingectomy) appeared as an attractive option for primary prevention of HGSC 3,11.

In this study, we aimed to analyze and explore the data of 1822 cases with EOC or primary peritoneal cancer (PPC) and 4339 cases with receiving salpingectomy on account of benign gynecological diseases from 2007 to 2017 in our centre in order to provide our experiences about the development and influence factors of salpingectomy. Additionally, we systematically reviewed the studies of opportunistic salpingectomy for ovarian cancer prevention.

\section{Material and methods}

\section{Ethics statement}

Institutional review board approval was obtained for this study, and informed patient consent was waived owing to the retrospective nature of the study.

\section{Study population}

Since January 1, 2007 until April 30, 2017, there were 1822 patients diagnosed and treated for EOC or PPC at Department of Gynecologic Oncology, Tianjin Medical University Cancer Institute and Hospital. The clinical data, including age, height, weight, menstrual history, child number, history of gynecologic surgery, gynecologic surgery types, histologic subtype, and FIGO stage, were extracted from available the patients' medical records (Table 1). Among them, 198 patients had a history of gynecological surgery because of benign diseases.

The eligible control women were collected from the database of our center. They received operation and were followed up more than 20 years until April 30, 2017, and had at least one intact ovary and fallopian tube. The controls $(n=389)$ had no history of ovarian cancer and were frequency matched to cases (2:1 ratio). Remarkably, there were not statistically different significances between the EOC group and the control group on age, body mass index (BMI), child number, and menopause status when choosing matched control cases (Table 2).

Table 1. Clinical characteristics of EOC and PPC patients

\begin{tabular}{ll}
\hline Characteristic & $\mathrm{N}(\%)$ \\
\hline Age(mean \pm SD), $\mathbf{y}$ & $52.59 \pm 9.2,52$ \\
$<52$ & 566 \\
$\geq 52$ & 1256 \\
Body mass index $\left(\mathbf{k g} / \mathbf{m}^{2}\right)$ & $25.29 \pm 3.52$ \\
Child number & \\
0 & $203(11.14)$ \\
$1-2$ & $960(52.69)$ \\
$>2$ & $659(36.17)$ \\
Menopause & \\
yes & $1302(71.46)$ \\
No & $520(28.54)$ \\
With history of gynecologic surgery & $\mathbf{1 9 8}(\mathbf{1 0 . 8 7 )}$ \\
Gynecologic surgery types & \\
Hysterectomy & $65(32.93)$ \\
USO & $48(24.24)$ \\
Hysterectomy and USO & $36(18.18)$ \\
Hysterectomy and bilateral salpingectomy & $24(12.12)$ \\
BSO & $14(7.07)$ \\
Hysterectomy and BSO & $11(5.56)$ \\
Without history of gynecologic surgery & $1624(89.13)$ \\
Histology & \\
Serous & $1292(70.91)$ \\
Mucinous & $194(10.65)$ \\
Endometrioid & $235(12.90)$ \\
Clear cell & $87(4.77)$ \\
Other* & $14(0.77)$ \\
FIGO Stage (2009) & \\
I-II & $529(29.03)$ \\
III-IV & $1293(70.97)$ \\
\hline EOC =Epithelial ovarian cancer; PPC= Primary peritoneal cancer; BSO=bilateral \\
salpingoophorectomy; USO=unilateral salpingoophorectomy; ${ }^{*}$ Other subtypes= \\
for example Brenner and squamous cell tumors & \\
&
\end{tabular}

Table 2. Characteristics of epithelial ovarian cancer cases and based controls

\begin{tabular}{lll}
\hline Characteristic & EOC $=198$ & Control =389 \\
\hline & Cases $(\mathrm{N}, \%)$ & Cases $(\mathrm{N}, \%)$ \\
Age(mean \pm SD), y & $52.31 \pm 12.4$ & $52.32 \pm 12.7$ \\
$<52$ & $86(43.4)$ & $168(43.2)$ \\
$\geq 52$ & $112(56.6)$ & $221(56.8)$ \\
Body mass index $\left(\mathbf{k g} / \mathbf{m}^{2}\right)$ & $25.47 \pm 5.5$ & $25.32 \pm 6.2$ \\
Child number & & \\
0 & $17(8.6)$ & $33(8.5)$ \\
$1-2$ & $121(61.1)$ & $237(60.9)$ \\
$>2$ & $60(30.3)$ & $119(30.6)$ \\
Menopause & & \\
yes & $109(55.1)$ & $214(55.0)$ \\
No & $89(44.9)$ & $175(45.0)$ \\
Salpingectomy & & \\
Yes & $133(67.2)$ & $304(78.1)$ \\
No & $65(32.8)$ & $85(21.9)$ \\
\hline
\end{tabular}

At the same period, there were 7404 patients receiving operation therapy in our centre owing to benign gynecological diseases. Among them, 4339 patients received unilateral or bilateral opportunistic salpingectomy because of benign gynecological 
diseases. The clinical information of these women, including age, height, weight, menstrual history, child number, marital status, economic status, family history of tumor, detailed clinical diagnosis, surgical route, operation time, and so on were extracted to analyze further (Table 3 ).

Table 3. Clinical characteristics of 4339 patients with benign disease and salpingectomy

\begin{tabular}{ll}
\hline Characteristic & $\mathrm{N}=4339(\%)$ \\
\hline Age(mean \pm SD, median), $\mathbf{y}$ & $55.1 \pm 7.82,55$ \\
$<55$ & $1068(24.61)$ \\
$\geq 55$ & $3271(75.39)$ \\
Body mass index $\left(\mathbf{k g} / \mathbf{m}^{2}\right)$ & $24.18 \pm 3.78$ \\
Child number & \\
0 & $384(8.85)$ \\
$1-2$ & $2287(52.71)$ \\
$>2$ & $1668(38.44)$ \\
Menopause & \\
yes & $3318(76.47)$ \\
No & $1021(23.53)$ \\
Marital status & \\
Unmarried & $857(19.75)$ \\
Married & $3482(80.25)$ \\
Educational status & \\
Middle school or less & $998(23.00)$ \\
High school & $2998(69.09)$ \\
College or more & $1341(30.91)$ \\
Income status & \\
Low & $898(20.70)$ \\
Median & $2392(55.13)$ \\
High & $1049(24.17)$ \\
Family history of tumor & \\
Yes & $2819(64.97)$ \\
No & $1520(35.03)$ \\
Family history of ovarian or breast cancer & \\
Yes & $411(9.47)$ \\
No & $3928(90.53)$ \\
Salpingectomy & \\
Unilateral & $1321(30.44)$ \\
Bilateral \\
Clinical diagnosis \\
Benign ovarian tumor \\
Adenomyosis/endometriosis & $3018(69.56)$ \\
Leiomyoma & \\
Pyosalpinx/salpingitis & $521(12.01)$ \\
Others & $937(21.59)$ \\
Surgical route & $2429(55.98)$ \\
Lapdominal hysterectomy $(A H)$ & $265(6.11)$ \\
Operation time (mean \pm SD), min & $187(4.31)$ \\
\hline & $3471(80.00)$ \\
\hline & $868(20.00)$ \\
\hline & $30 \pm 20$ \\
\hline
\end{tabular}

\section{Statistical analysis}

Continuous data and frequency data were analyzed by Fisher's exact test and the chi-square test. Description of categorical variables was used as rate (\%) and description of continuous variables were expressed as mean \pm standard deviation (SD). Logistic regression analysis was used to estimated ORs and 95\% CIs for developing ovarian cancer in association with salpingectomy. Two-sided P-values were considered statistically significant at $\mathrm{P} \leq 0.05$. Statistical analysis was performed using SPSS software passage for Windows (version 20.0; SPSS Inc., Chicago, IL, USA).

\section{Results}

\section{Salpingectomy reducing the risk of EOC}

We identified 1822 patients with a diagnosis of EOC or PPC from 2007 to 2017 in our centre. Extracting the data of past medical history, we found there were 198 patients with a history of gynecological surgery because of benign diseases. Among them, 65 cases had the history of hysterectomy (33\%); 48 cases had the history of receiving unilateral salpingoophorectomy (USO) therapy (24\%); 36 cases had history of receiving hysterectomy and USO (18\%); 24 cases had operation history of receiving hysterectomy and bilateral salpingectomy (12\%); 14 cases had history of bilateral salpingoophorectomy (BSO) therapy (7\%); 11 cases had history of receiving hysterectomy and BSO (6\%) (Figure 1). Then, by using of conditional logistic regression statistical analysis, salpingectomy reduced overall EOC risk in the age-adjusted model (OR=1.750; 95\% CI=1.194-2.564; $P=0.004)$. Similarly, in multivariate models, including age, child number, and menopause status, women who had salpingectomy had a lower risk of ovarian cancer compared to women without receiving salpingectomy $\quad(\mathrm{OR}=2.080 ; \quad 95 \% \quad \mathrm{CI}=1.340-3.227$; $P=0.001)$. Thus, the incidence of EOC was significantly decreased in the population with salpingectomy, compared to women with fallopian tube reserved according to population control-base analysis.

\section{Rate of salpingectomy increasing annually from 2007 to 2017}

In 2007, 336 women with benign gynecological disease received operation therapy in our centre and there 74 cases were performed by bilateral salpingectomy among them. Surprisingly, there already 112 patients with benign gynecological disease received bilateral salpingectomy among 186 operation cases in our centre from January to April in 2007. We found the overall rate of bilateral salpingectomy was gradually increased in our centre from 2007 to 2017 (from 22.02\% to 60.22\%), which showed approximately threefold increase in a decade (Table 4, Figure 2).

\section{Factors affecting the rate of salpingectomy in our centre}

There were 7404 patients receiving operation therapy owing to benign gynecological diseases in our centre from 2007 to 2017. Among them, 4339 patients received unilateral or bilateral opportunistic salpingectomy because of benign gynecological 
diseases, compared with 3065 cases without salpingectomy. The detailed data of clinical characteristics about these two groups patients was analyzed by chi-square test and listed in table 5 . In age subgroup analysis, the rate of salpingectomy of patients with $\geq 55$ years was significantly higher than that of the subgroup with < 55 years $(75 \%$ vs $25 \%$ and $20 \%$ vs $80 \%, P<0.001)$. In menstrual status subgroups analysis, the rate of salpingectomy in menopause women population was higher than that in premenopausal women obviously ( $76 \%$ vs $24 \%$ and $29 \%$ vs $71 \%, P<0.001)$. In marital status subgroups analysis, the results indicated the married women population preferred to receive salpingectomy operation comparing with the unmarried women ( $80 \%$ vs $20 \%$ and $72 \%$ vs $20 \%, P<0.001)$. We also found that the rate of salpingectomy in patients with better educational population was apparently high, compared to the patient with middle school or less educational status $(31 \%+46 \%=77 \%$ vs $23 \%$ and $31 \%+40 \%=71$ vs $29 \%, P<0.001)$. Additionally, it was easier for patients with better economic status to choose salpingectomy, compared to the patient with low income status $(24 \%+55 \%=79 \%$ vs $21 \%$, and $21 \%+51 \%=72 \%$ vs $28 \%, P<0.001)$. Moreover, the rate of salpingectomy in women with one child or more was significantly higher than that in women without child $(53 \%+38 \%=91 \%$ vs $9 \%$ and $15 \%+51 \%=66 \%$ vs

$34 \%, P<0.001$. Furthermore, the rate of salpingectomy in patients with family history of tumor was higher than that in patients without family history of tumor ( $65 \%$ vs $35 \%$ and $34 \%$ vs $66 \%, P<0.001$ ). In general, factors affecting the rate of salpingectomy included age, child number, menopause or not, marital status,

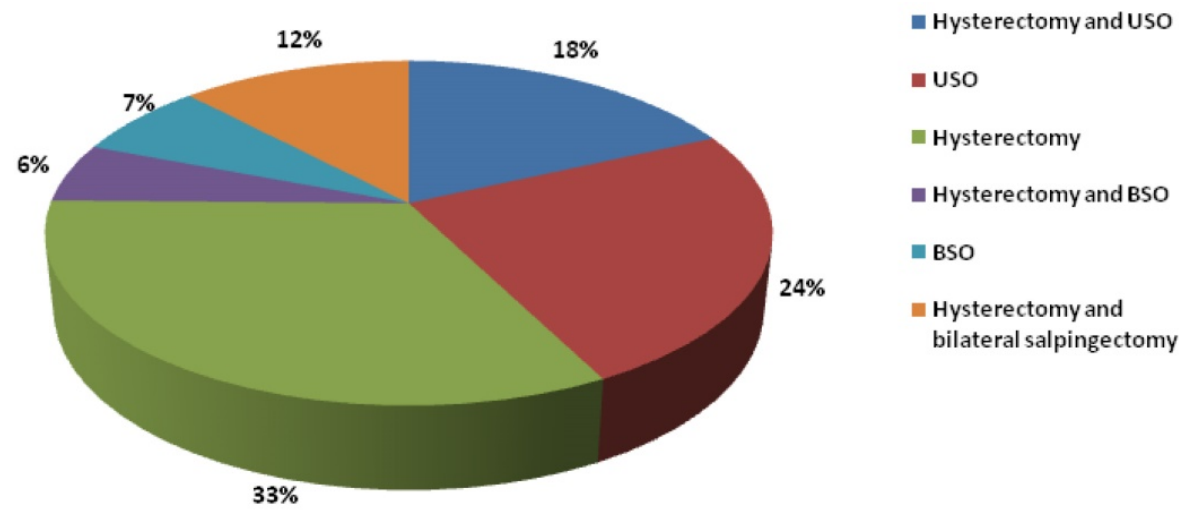

Figure 1. There were 198 patients with a history of gynecological surgery because of benign diseases in our centre. Among them, 65 cases had the history of hysterectomy (33\%); 48 cases had the history of receiving unilateral salpingoophorectomy (USO) therapy (24\%); 36 cases had history of receiving hysterectomy and USO (18\%); 24 cases had operation history of receiving hysterectomy and bilateral salpingectomy (12\%); 14 cases had history of bilateral salpingoophorectomy (BSO) therapy (7\%); 11 cases had history of receiving hysterectomy and BSO (6\%). educational status, income status, and with or without family history of tumor (table 5).

Table 4. The Rate of Bilateral Salpingectomy in our centre from 2007 to 2017

\begin{tabular}{llll}
\hline Year & $\begin{array}{l}\text { Bilateral } \\
\text { salpingectomy } \\
\text { Cases (n) }\end{array}$ & $\begin{array}{l}\text { Benign diseases } \\
\text { operation cases }(\mathrm{n})\end{array}$ & $\begin{array}{l}\text { The rate of bilateral } \\
\text { salpingectomy }(\%)\end{array}$ \\
\hline 2007 & 74 & 336 & 22.02 \\
2008 & 132 & 471 & 28.03 \\
2009 & 218 & 703 & 31.01 \\
2010 & 263 & 751 & 35.02 \\
2011 & 286 & 785 & 36.43 \\
2012 & 307 & 682 & 45.01 \\
2013 & 352 & 721 & 48.82 \\
2014 & 386 & 743 & 51.95 \\
2015 & 411 & 758 & 54.22 \\
2016 & 477 & 799 & 59.70 \\
2017 & 112 & 186 & 60.22 \\
Total & 3018 & 6935 & \\
\hline
\end{tabular}

\section{Discussion}

As we known, ovarian cancer is a heterogeneous disease that can be divided into three main types: sex cord stromal tumors, germ cell tumors, and EOC ${ }^{12}$. EOC accounts for the vast majority of ovarian cancers and consists of different subtypes, including HGSC, low-grade serous, mucinous, endometrioid, clear cell, and so on. The various histotypes differ in epidemiology, etiology, and treatment. HGSC is the most common and aggressive subtype of EOC, which accounts for $75 \%$ of cases 9 . Molecular and genetic data indicate that HGSC of the ovary may have a similar origin to HGSC of the fallopian tube and peritoneum, and therefore, it has been suggested that all the three be described collectively as HGSC ${ }^{13}$.

Recently, accumulative literature demonstrated the fallopian tube was the original site of EOC and the initial evidence was considered from the studies of prophylactic salpingoophorectomy in women bearing BRCA mutations 14-16. Carefully examination of fallopian specimens revealed dysplastic lesions, later designated as STIC located in the fimbrial end ${ }^{17}$. With emphasis, the precursor lesions have never been found in the ovarian epithelium. There is additional evidence supporting the concept of the fallopian origin of ovarian HGSC that the gene expression profile of HGSC is closely related to fallopian tube epithelium rather than to the ovarian surface epithelium 9. Moreover, in a 
mouse model, Kim and his colleagues showed that the removal of the fallopian tubes, but not removal of the ovaries, prevents HGSC formation 18. Therefore, opportunistic bilateral salpingectomy (OBS) (also called prophylactic salpingectomy and riskreducing salpingectomy) at the time of pelvic or abdominal surgery for a benign condition has been recommended by several associations and experts ${ }^{19-26}$ (Table 6).

Table 5. Factors affecting the rate of salpingectomy in our centre

\begin{tabular}{|c|c|c|c|}
\hline \multirow[t]{2}{*}{ Characteristic } & \multicolumn{2}{|l|}{$\mathrm{N}=7404$} & \multirow[t]{2}{*}{$\mathrm{P}$} \\
\hline & $\begin{array}{l}\text { With salpingectomy } \\
\mathrm{N}=4339(\%)\end{array}$ & $\begin{array}{l}\text { Without } \\
\text { salpingectomy } \\
\mathrm{N}=3065(\%)\end{array}$ & \\
\hline $\begin{array}{l}\text { Age(mean } \pm S D, \text { median), } \\
\text { y }\end{array}$ & $55.1 \pm 7.82,55$ & & $<0.001$ \\
\hline$<55$ & $1068(25)$ & 2452(80) & \\
\hline$\geq 55$ & $3271(75)$ & $613(20)$ & \\
\hline Body mass index $\left(\mathrm{kg} / \mathrm{m}^{2}\right)$ & $24.18 \pm 3.78$ & $23.98 \pm 9.78$ & \\
\hline Child number & & & $<0.001$ \\
\hline 0 & $384(9)$ & $1046(34)$ & \\
\hline $1-2$ & $2287(53)$ & $1571(51)$ & \\
\hline$>2$ & $1668(38)$ & $448(15)$ & \\
\hline Menopause & & & $<0.001$ \\
\hline yes & $3318(76)$ & $878(29)$ & \\
\hline No & $1021(24)$ & $2187(71)$ & \\
\hline Marital status & & & $<0.001$ \\
\hline Unmarried & $857(20)$ & $844(28)$ & \\
\hline Married & $3482(80)$ & $2221(72)$ & \\
\hline Educational status & & & $<0.001$ \\
\hline Middle school or less & $998(23)$ & $889(29)$ & \\
\hline High school & $1998(46)$ & $1226(40)$ & \\
\hline College or more & $1343(31)$ & $950(31)$ & \\
\hline Income status & & & $<0.001$ \\
\hline Low & $898(21)$ & $850(28)$ & \\
\hline Median & $2392(55)$ & $1575(51)$ & \\
\hline High & $1049(24)$ & $640(21)$ & \\
\hline Family history of tumor & & & $<0.001$ \\
\hline Yes & $2819(65)$ & 1034(34) & \\
\hline No & $1520(35)$ & $2031(66)$ & \\
\hline
\end{tabular}

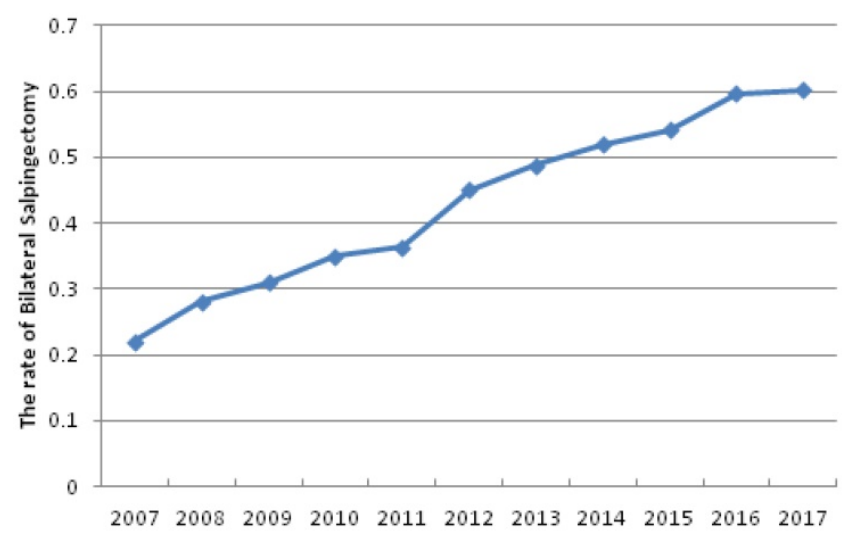

Figure 2. The overall rate of bilateral salpingectomy was gradually increased in our centre from 2007 to 2017 (from $22.02 \%$ to $60.22 \%$ ), which showed approximately threefold increase in a decade.
Table 6. Chronological Statements of Gynecological Boards on Opportunistic Salpingectomy

\begin{tabular}{|c|c|c|}
\hline Year & $\begin{array}{l}\text { Associations or } \\
\text { Experts }\end{array}$ & Recommendation \\
\hline 2011 & $\begin{array}{l}\text { Canadian } \\
\text { gynecological } \\
\text { group }^{19}\end{array}$ & $\begin{array}{l}\text { Consider surgical removal of fallopian tubes at } \\
\text { the time of hysterectomy, even when ovaries } \\
\text { were conserved } \\
\text { Replace tubal ligation with excision bilateral } \\
\text { salpingectomy for the purpose of permanent } \\
\text { contraception } \\
\text { Refer all patients with HGSC for hereditary } \\
\text { cancer counseling and genetic testing for } \\
\text { BRCA1/2 mutations }\end{array}$ \\
\hline 2011 & $\begin{array}{l}\text { Royal Australian and } \\
\text { new Zealand college } \\
\text { of obstetricians and } \\
\text { gynecologists } 18\end{array}$ & $\begin{array}{l}\text { Doctors should discuss the risks and benefits of } \\
\text { bilateral salpingectomy with patients } \\
\text { undergoing by hysterectomy for benign disease }\end{array}$ \\
\hline 2013 & $\begin{array}{l}\text { Society of } \\
\text { Gynecologic } \\
\text { Oncology (SGO) })^{21,22}\end{array}$ & $\begin{array}{l}\text { For women at average risk of ovarian cancer, } \\
\text { risk-reducing salpingectomy should also be } \\
\text { discussed and considered with patients at the } \\
\text { time of abdominal or pelvic surgery, } \\
\text { hysterectomy or in lieu of tubal ligation }\end{array}$ \\
\hline 2013 & $\begin{array}{l}\text { Committee on } \\
\text { gynecologic } \\
\text { practice }^{22}\end{array}$ & $\begin{array}{l}\text { Prophylactic salpingectomy may offer clinicians } \\
\text { the opportunity to prevent ovarian cancer in } \\
\text { their patients. Randomized controlled trials are } \\
\text { needed to support the validity of this approach } \\
\text { to reduce the incidence of ovarian cancer }\end{array}$ \\
\hline 2014 & $\begin{array}{l}\text { Royal college of } \\
\text { Obstetricians and } \\
\text { Gynecologist } 25\end{array}$ & $\begin{array}{l}\text { Women who are not at high risk for BRCA } \\
\text { mutation and have completed their families } \\
\text { should be carefully considered for prophylactic } \\
\text { removal of the fallopian tubes with conservation } \\
\text { of ovaries at the time of gynecological or other } \\
\text { intraepritoneal surgery }\end{array}$ \\
\hline 2015 & $\begin{array}{l}\text { American college of } \\
\text { obstetricians and } \\
\text { gynecologists } \\
(\mathrm{ACOG})^{20}\end{array}$ & $\begin{array}{l}\text { Women at population-level risk of ovarian } \\
\text { cancer who are undergoing ovary-sparing } \\
\text { hysterectomy for benign indications should be } \\
\text { offered bilateral salpingectomy to reduce their } \\
\text { risk of ovarian cancer }\end{array}$ \\
\hline 2015 & $\begin{array}{l}\text { Commission Ovary } \\
\text { of the } \mathrm{AGO}^{24}\end{array}$ & $\begin{array}{l}\text { During preoperative counseling prior to } \\
\text { hysterectomy, all patients should be informed } \\
\text { about the potential beneficial impact of } \\
\text { opportunistic salpingectomy and the associated } \\
\text { risks }\end{array}$ \\
\hline 2016 & $\begin{array}{l}\text { American cancer of } \\
\text { association } 23\end{array}$ & $\begin{array}{l}\text { Opportunistic salpingectomy to patients as an } \\
\text { opportunistic procedure during benign } \\
\text { hysterectomies and as an alternative to bilateral } \\
\text { tubal ligation for sterilization procedures }\end{array}$ \\
\hline
\end{tabular}

Meanwhile, we summarized and analyzed the rate of salpingectomy for the benign gynecologic condition in our centre from 2007 to 2017. The results revealed that the overall rate of bilateral salpingectomy was annually increased in from $22.02 \%$ to $60.22 \%$, approaching threefold increase in a decade. Moreover, factors affecting people determined to perform salpingectomy or not included age, child number, menopause or not, marital status, educational status, income status, and with or without family history of tumor, in fact, which involved the perceptions of public and gynecologists about prophylactic salpingectomy for preventing ovarian cancer in China. In Korea, towards to general population, the questionnaires were distributed to 100 healthy female volunteers. Questionnaire for this survey included questions on demographics, medical history, knowledge of and belief about risk-reducing 
salpingectomy (RRS), and barrier to its application. Among 100 respondents, $71 \%$ did not realize the seriousness of ovarian cancer, $79 \%$ were unaware of the fact that salpinx was the origin of ovarian cancer, and $87 \%$ stated that they had never heard of RRS as a preventive method for ovarian cancer. The authors suggested physicians should discuss RRS with patients and consider this procedure at the time of abdominal or pelvic surgery ${ }^{29}$. Correspondingly, in order to examine Italian obstetrician-gynecologists' knowledge, a survey was conducted to gather their opinions about prophylactic bilateral salpingectomy (PBS) for the prevention of ovarian cancer and assess current clinical practice and willingness to incorporate salpingectomy into surgical interventions (benign indications). A total of 479 surveys were returned. At least $80 \%$ respondents reported performing PBS during hysterectomy for benign indications, chiefly with the intent of ovarian cancer risk reduction and decreasing the risk of reoperation and subsequent tubal pathologies. PBS as a prophylactic measure to reduce the incidence of ovarian cancer is a well-known strategy among the Italian gynecologists interviewed. Finally, the author suggested wider educational initiatives should be undertaken to increase the implementation of salpingectomy in Italy ${ }^{30}$.

However, there are limitations of our study. Firstly, our study just is a retrospective summarization of the patients' literature of our centre, there is a great need for prospective and large scale studies to evaluate the safety and efficacy of salpingectomy as a preventive strategy for ovarian cancer. Secondly, considering our results from a single centre, the multi-centre study should be taken in order to provide more information of opportunistic salpingectomy from general population in China. Additionally, our study based on 10 years experiences and absence long period follow-up for estimate the validity of decreasing morbidity of ovarian cancer, even for prediction of survival and prognosis for these new EOC cases. Thus, the longer follow up and summarization of theses enrolled patients should be performed in the future.

Conclusively, the incidence of EOC was significantly decreased in the population with salpingectomy in our centre, compared to women with fallopian tube reserved. Furthermore, the overall rate of bilateral salpingectomy was annually increased from 2007 to 2017, which effected by several factors, including age, child number, menopause or not, marital status, educational status, economic status, and with or without family history of tumor. Therefore, based on comprehensive assessment, it is recommended that appropriate patients should be discussed to perform applicable opportunist bilateral salpingectomy at the time of receiving benign gynecological surgery for preventing ovarian cancer.

\section{Acknowledgement}

This work was supported by National Natural Science Foundation (81302250) and Tianjin Health Bureau of Science and Technology Funds (2012KZ073).

\section{Competing Interests}

The authors have declared that no competing interest exists.

\section{References}

1. Siegel RL, Miller KD, Jemal A. Cancer Statistics, 2017. CA Cancer J Clin 2017;67:7-30.

2. Webb PM, Jordan SJ. Epidemiology of epithelial ovarian cancer. Best Pract Res Clin Obstet Gynaecol 2017;41:3-14.

3. Zietek A, Bogusiewicz M, Szumilo J, et al. Opportunistic salpingectomy for prevention of sporadic ovarian cancer - a jump from basic science to clinical practice? Ginekol Pol 2016;87:467-72.

4. Guth U, Huang DJ, Bauer G, et al. Metastatic patterns at autopsy in patients with ovarian carcinoma. Cancer-Am Cancer Soc 2007;110:1272-80.

5. Lin SF, Gerry E, Shih IM. Tubal origin of ovarian cancer - the double-edged sword of haemoglobin. J Pathol 2017;242:3-6.

6. George SH, Garcia R, Slomovitz BM. Ovarian Cancer: The Fallopian Tube as the Site of Origin and Opportunities for Prevention. Front Oncol 2016;6:108.

7. Longacre TA, Oliva E, Soslow RA. Recommendations for the reporting of fallopian tube neoplasms. Virchows Arch 2007;450:25-9.

8. Singh N, McCluggage WG, Gilks CB. High grade serous carcinoma (HGSC) of tubo-ovarian origin: recent developments. Histopathology 2017.

9. Kurman RJ, Shih I. Molecular pathogenesis and extraovarian origin of epithelial ovarian cancer--shifting the paradigm. Hum Pathol 2011;42:918-31.

10. Koshiyama M, Matsumura N, Konishi I. Recent concepts of ovarian carcinogenesis: type I and type II. Biomed Res Int 2014;2014:934261.

11. Kho RM, Wechter ME. Operative Outcomes of Opportunistic Bilateral Salpingectomy at the Time of Benign Hysterectomy in Low-Risk Premenopausal Women: A Systematic Review. J Minim Invasive Gynecol 2017;24:218-29.

12. George SH, Shaw P. BRCA and Early Events in the Development of Serous Ovarian Cancer. Front Oncol 2014;4:5

13. Chen F, Gaitskell K, Garcia MJ, et al. Serous tubal intraepithelial carcinomas associated with high-grade serous ovarian carcinomas: a systematic review. BJOG 2017;124:872-8.

14. Akbari MR, Donenberg T, Lunn J, et al. The spectrum of BRCA1 and BRCA2 mutations in breast cancer patients in the Bahamas. Clin Genet 2014;85:64-7.

15. Salvador S, Scott S, Francis JA, et al. No. 344-Opportunistic Salpingectomy and Other Methods of Risk Reduction for Ovarian/Fallopian Tube/Peritoneal Cancer in the General Population. J Obstet Gynaecol Can 2017;39:480-93.

16. Lessard-Anderson CR, Handlogten KS, Molitor RJ, et al. Effect of tubal sterilization technique on risk of serous epithelial ovarian and primary peritoneal carcinoma. Gynecol Oncol 2014;135:423-7.

17. Ayres C, Ratnayake G, McNally O, et al. Challenging Salpingectomy as a Risk-Reducing Measure for Ovarian Cancer: Histopathological Analysis of the Tubo-Ovarian Interface in Women Undergoing Risk-Reducing Salpingo-oophorectomy. Int J Gynecol Cancer 2017;27:703-7.

18. Kim J, Coffey DM, Creighton CJ, et al. High-grade serous ovarian cancer arises from fallopian tube in a mouse model. Proc Natl Acad Sci U S A 2012;109:3921-6.

19. Brand AH. The RANZCOG College Statement on prophylactic oophorectomy in older women undergoing hysterectomy for benign disease: is the evidence sufficient to change practice? Aust N Z J Obstet Gynaecol 2011;51:296-300.

20. Canada TSOG. GOC statement regarding salpingectomy and ovarian cancer prevention. In; 2011.

21. Committee on Gynecologic Practice. Committee opinion no. 620: Salpingectomy for ovarian cancer prevention. Obstet Gynecol 2015;125:279-81.

22. Walker JL, Powell CB, Chen LM, et al. Society of Gynecologic Oncology recommendations for the prevention of ovarian cancer. Cancer-Am Cancer Soc 2015;121:2108-20.

23. SGO. SGO Clinical Practice Statement: Salpingectomy for Ovarian Cancer Prevention. 2013.

24. Cancer. OCIF. National Comprehensive Cancer Network NCCN Clinical Practice Guidelines in Oncology (NCCN Guidelines). In; 2016. 
25. Polcher M, Hauptmann S, Fotopoulou C, et al. Opportunistic salpingectomies for the prevention of a high-grade serous carcinoma: a statement by the Kommission Ovar of the AGO. Arch Gynecol Obstet 2015;292:231-4.

26. Gynaecologists. RCOO. The Distal Fallopian Tube as the Origin of Non-Uterine Pelvic High-Grade Serous Carcinomas. Scientific Impact Paper 2014;44:1-8.

27. Madsen C, Baandrup L, Dehlendorff C, et al. Tubal ligation and salpingectomy and the risk of epithelial ovarian cancer and borderline ovarian tumors: a nationwide case-control study. Acta Obstet Gynecol Scand 2015;94:86-94.

28. Falconer $\mathrm{H}$, Yin $\mathrm{L}$, Gronberg $\mathrm{H}$, et al. Ovarian cancer risk after salpingectomy: a nationwide population-based study. J Natl Cancer Inst 2015;107.

29. Kang JH, Nam SH, Song $\mathrm{T}$, et al. Public perception of risk-reducing salpingectomy for preventing ovarian cancer. Obstet Gynecol Sci 2015;58:284-8.

30. Venturella R, Rocca M, Lico D, et al. Prophylactic bilateral salpingectomy for the prevention of ovarian cancers: What is happening in Italy? Eur J Cancer Prev 2016;25:410-5. 